\title{
Influence of Mechanical Stress on the Potential Distribution on a 301 LN Stainless Steel Surface
}

\author{
N. Fuertes Casals, ${ }^{a, z}$ A. Nazarov, ${ }^{b, *}$ F. Vucko, ${ }^{b}$ R. Pettersson, ${ }^{c}$ and D. Thierry ${ }^{b, *}$ \\ ${ }^{a}$ Swerea KIMAB AB, Stockholm, Sweden \\ ${ }^{b}$ French Corrosion Institute, Brest, France \\ ${ }^{c}$ Jernkontoret, Stockholm, Sweden
}

\begin{abstract}
The aim of the present work was to study the influence of the stress on the electrode potential of the austenitic stainless stee 301LN using Scanning Kelvin Probe (SKP). It was found that elastic deformation reversibly ennobles the potential whereas plastic deformation decreases the potential in both tensile and compressive deformation mode and this decrease is retained even $24 \mathrm{~h}$ after removal of the load. To interpret the stress effects, different surface preparations were used and the composition and thickness of the passive film were determined by GDOES. Slip steps formed due to plastic deformation were observed using AFM. The effect of plastic strain on the potential is explained by the formation of dislocations, which creates more a defective passive film.

(C) The Author(s) 2015. Published by ECS. This is an open access article distributed under the terms of the Creative Commons Attribution 4.0 License (CC BY, http://creativecommons.org/licenses/by/4.0/), which permits unrestricted reuse of the work in any medium, provided the original work is properly cited. [DOI: 10.1149/2.0511509jes] All rights reserved.
\end{abstract}

Manuscript submitted May 4, 2015; revised manuscript received June 12, 2015. Published June 24, 2015. This was Paper 790 presented at the Cancun, Mexico, Meeting of the Society, October 5-9, 2014.

Stainless steels are used in industrial and construction applications in which a corrosive environment and mechanical loads are often combined. The high corrosion resistance of stainless steel is ensured by the presence of a chromium-enriched passive film that protects the steel from corrosive species. External mechanical loads and residual stresses can affect the integrity of the passive film, which can decrease the protectiveness of the oxide. For instance, one of the established mechanisms for stress corrosion cracking (SCC) is based on the concept that tensile stress breaks the passive film creating anodic locations at the bottom of the crack $^{1-3}$ which propagate through a activation/passivation process. Hence, the study of the influence of mechanical stress on the electrochemical and physical properties of the passive film is crucial for the understanding of common corrosion processes in stainless steel.

Previous studies have shown that the passive film thickness decreased when the stainless steel was under load, ${ }^{4}$ with a greater effect for tensile than compressive load. ${ }^{5}$ Load also affects the electrochemical properties of passive films; the polarization resistance of the steel decreases and its capacitance and conductivity increase when external elastic or plastic load is applied. ${ }^{5-7}$ These changes can be explained by a rupture of the oxide and by an increased number of oxygen vacancies under a stress state, subsequently increasing the amount of donors and acceptors. ${ }^{5,8-10}$ Dislocations generated during loading give rise to a less protective passive film and decrease the ability of the steel to repassivate. ${ }^{11-14}$ At the same time, deformation can cause the transformation of austenite to $\alpha$-martensite in metastable austenitic stainless steels when this is loaded, e.g. cold rolling and plastic deformation. ${ }^{9}$ Martensite formation can also rupture the passive film and decrease its essence of protectiveness. ${ }^{13}$

The Scanning Kelvin Probe (SKP) is a potentially useful method to examine the effect of load on the corrosion resistance of passive film, because it allows in-situ quantification of the surface electrochemical potential. SKP measures the electrochemical potential of the material relative to a reference electrode or the electron work function $(E W F, \Phi)$ relative to zero level in vacuum. The term Volta potential is commonly used in the literature to denote the parameter measured by SKP. However, the Volta potential is a result of charge on the surface and is affected by the probe and geometric factors. Hence, the Volta potential is not a characteristic parameter and the term electrode potential will be used instead in this work..$^{15,16}$

$\Phi$ can be subdivided into a contribution of the metal bulk $\left(\mu_{\mathrm{e}}\right)$ and the potential drop at the metal-vacuum interface $(\chi)$, where $e$ is

\footnotetext{
*Electrochemical Society Active Member.
}

${ }^{\mathrm{z}}$ E-mail: nuria.fuertes@swerea.se electron charge. ${ }^{16}$

$$
\Phi=\mu_{\mathrm{e}}-\mathrm{e} \chi
$$

The electron work function will be affected when plastic load is applied as $\chi$ is dependent on the crystallographic structure and interatomic distance. ${ }^{17-19}$

Other parameters influence the EWF on metal with a semiconducting oxide on its surface. The potential drop across the metal-oxide-air interfaces has two contributions. The drop at the metal-oxide interface relates to difference of Fermi levels in the metal and in the oxide before two materials are in contact. The drop at the oxide-air interface corresponds to the electron band bending in the oxide due to adsorption and the formation of a dipole layer on the oxide surface. ${ }^{19}$

A number of previous works have shown an effect of load on electrochemical potential. ${ }^{20-26}$ A clear difference was observed between the effect of elastic and plastic loads on the EWF. For elastic loads it was considered that the stress mainly influences the potential drop across the metal/vacuum interface due to the changing in the distance between surface atoms, while the change of the chemical potential in the metal bulk is negligible. ${ }^{22,24}$ For plastic loads, the stress above the yield point creates plastic deformation with the generation of dislocations. ${ }^{20,21,24-27}$ The changing of EWF after elastic and plastic strains has also been analyzed for stainless steel. ${ }^{23,26}$ For the duplex grade AISI S31803 it was observed that during strain ferrite had a lower potential than austenite and that elastic deformation increased EWF by $0.020-0.025 \mathrm{eV}$ whereas plastic deformation decreased the EWF $0.3 \mathrm{eV}$. The change of EWF due to elastic deformation was explained due to an increase of the nano-surface roughness whereas the effect of plastic deformation was described by an increase by the formation of dislocations and slip bands. A similar response was observed on plastically deformed austenitic grade $304,{ }^{26}$ showing that plastic strain decreased the potential by $150 \mathrm{mV}$. This was related to the rupture of oxide after formation of dislocations.

The significance of the SKP measurement is seen when it can be correlated to the corrosion potential, which in turn is an indicator of the corrosion resistance. It has been shown experimentally that depending on the environment, the potential $(\Phi / \mathrm{e})$ of the metal surface can be correlated to the corrosion potential (e.g. for corroding metals) $)^{15,28,29}$ or to the metal potential in the passive state (e.g. in dry air or in vacuum). ${ }^{15}$

Consequently, the effect of external applied load on the corrosion resistance of stainless steel can be assessed by studying the electrode potential and the properties and changes of the passive film. In this work, SKP was used to study the effect of plastic and elastic loading on the electrode potential of austenitic stainless steel 301LN based on the changes of the passive film properties during loading. In order to 
Table I. Chemical composition of the investigated material [wt \%]. Balance Fe.

\begin{tabular}{ccccccccccc} 
Material & $\mathrm{EN}$ & $\mathrm{C}$ & $\mathrm{Si}$ & $\mathrm{Mn}$ & $\mathrm{P}$ & $\mathrm{S}$ & $\mathrm{Cr}$ & $\mathrm{Ni}$ & $\mathrm{Mo}$ & $\mathrm{N}$ \\
\hline 301LN & 1.4318 & 0.029 & 0.43 & 1.27 & 0.031 & 0.001 & 17.6 & 6.55 & 0.17 & 0.138
\end{tabular}

obtain a baseline for comparison, the effect of surface preparation and elapsed time after surface preparation was also evaluated.

\section{Experimental}

In this study the austenitic stainless steel 301LN (EN 1.4318, Coil 703953, thickness $3 \mathrm{~mm}$ ) provided by Outokumpu Stainless AB was investigated. The nominal composition is listed in Table I.

The material was investigated in the temper rolled condition, which means that substantial work hardening and deformation martensite were present. The mechanical properties, determined by tensile testing, using the geometry shown in Fig. $1 \mathrm{C}$ are given in Table II. As a comparison, the proof stress of fully annealed material of the same grade is typically just below $400 \mathrm{MPa}$.

Scanning Kelvin Probe.- A UBM Messtechnick Scanning Kelvin Probe (SKP) was used for measurements of the surface distribution of electrode potential. The Kelvin capacitor consists of two metallic electrodes separated by an air gap. Mechanical vibrations of the probe above the working electrode create an alternating capacitor and flow of an alternating current (see Eq. 2) 15,30 $^{15}$

$$
\begin{gathered}
\mathrm{I}(\mathrm{t})=\Delta \mathrm{V}_{\mathrm{p} / \mathrm{w}}\left(\mathrm{dC}_{\mathrm{p} / \mathrm{w}} / \mathrm{dt}\right) \\
\Delta \mathrm{V}_{\mathrm{p} / \mathrm{w}}=\left(\Phi_{\mathrm{w}}-\Phi_{\mathrm{P}}\right) / \mathrm{e}^{-}
\end{gathered}
$$

where $I(t)$ is the alternating current, $C_{p / w}$ is the alternating capacitance, $\Delta \mathrm{V}_{\mathrm{p} / \mathrm{w}}$ is the contact potential difference between probe and specimen, $\mathrm{e}^{-}$refers to the electron charge, $\Phi_{\mathrm{w}}$ and $\Phi_{\mathrm{P}}$ are the electrochemical work functions, EWF, of the specimen and probe surfaces, respectively. The potential drop $\Delta \mathrm{V}_{\mathrm{p} / \mathrm{w}}$ within the air gap reflects the difference in electrode potentials $(\Phi / \mathrm{e})$ and thus the difference in the corresponding EWF (Eq. 3). ${ }^{30}$ Because the potential of the probe $\left(\Phi_{\mathrm{P}} / \mathrm{e}\right)$ remains constant and is calibrated against a reference electrode $\mathrm{Cu} / \mathrm{CuSO}_{4}$, the potential $\left(\Phi_{\mathrm{w}} / \mathrm{e}\right)$ or work function $\left(\Phi_{\mathrm{w}}\right)$ of the specimen surface can be obtained.

The tests were carried out in laboratory air at ambient temperature and humidity $\left(50 \% \mathrm{RH}\right.$ and $\left.22^{\circ} \mathrm{C}\right)$. To keep the probe-specimen distance constant during the mapping, topography measurements were carried out before the potential measurements. The topography accuracy is in the range $1-2 \mu \mathrm{m}$. The gap between electrodes was adjusted to 30 or $50 \mu \mathrm{m}$, the vibration amplitude was $20 \mu \mathrm{m}$ and the vibration frequency was around $2 \mathrm{kHz}$. The reference electrode is a needle of a Ni-Cr alloy with a tip diameter of $100 \mu \mathrm{m}$ and the lateral resolution was in the range of $100 \mu \mathrm{m}$. In standard measurements, the
A

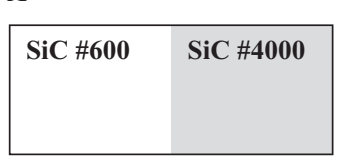

B

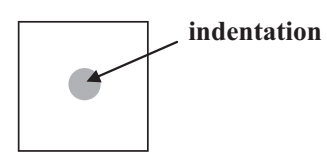

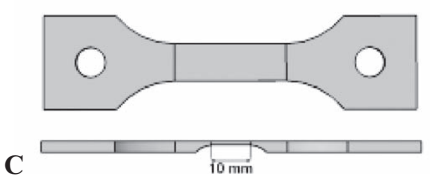

Figure 1. Sketch of SKP specimens for (A) surface polishing- electrode potential studies and (B) compression-electrode potential studies (C) tensileelectrode potential studies.

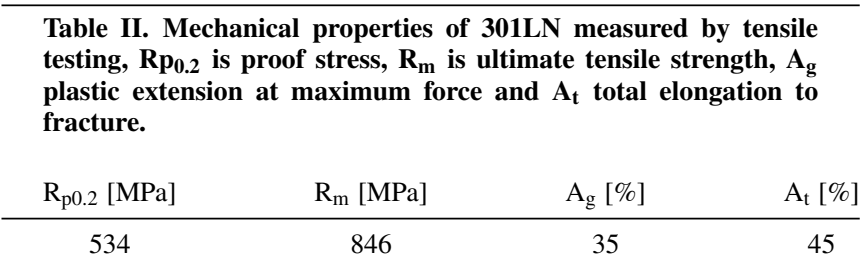

data recording density was 16 points/mm (X-axis) and 4 points $/ \mathrm{mm}$ (Y-axis). Before measurements, the potential of the probe was calibrated against a saturated $\mathrm{Cu} / \mathrm{CuSO}_{4}$ electrode. All SKP potentials are given versus the standard hydrogen electrode (SHE).

Three types of specimens were used for SKP measurements depending on the final purpose of study.

For studying the influence of surface roughness on the electrode potential, the entire top surface of the specimen, of dimensions $10 \times 4 \times 3 \mathrm{~mm}$, was prepared by grinding or polishing. Surface finishes between $\mathrm{SiC} \# 80$ grit and $1 \mu \mathrm{m}$ diamond paste were used.

Unless otherwise specified, the steel surface for SKP measurements was prepared, rinsed in de-ionized water then exposed for $48 \mathrm{~h}$ to dry air in order to form a reproducible passive film. In some cases parts of the surface were carefully abraded at a predetermined time before testing and in one case the specimen was firstly polished using $\mathrm{SiC} \mathrm{\# 600} \mathrm{and} \mathrm{subsequently} \mathrm{half} \mathrm{of} \mathrm{it} \mathrm{was} \mathrm{manually} \mathrm{polished} \mathrm{with} \mathrm{SiC}$ $\# 4000$, as shown in Fig. 1A. Some specimens were first $1 \mu \mathrm{m}$ diamond paste polished and then immersed in 30 vol. $\% \mathrm{HNO}_{3}$, at $22^{\circ} \mathrm{C}$ for $30 \mathrm{~min}$ while others were first $1 \mu \mathrm{m}$ diamond paste polished and then heat-treated at $150^{\circ} \mathrm{C}$ in air for $18 \mathrm{~h}$ in order to study the effect of these processes on the oxide and electrode potential. The stressed specimens were tested $48 \mathrm{~h}$ after polishing with $1 \mu \mathrm{m}$ diamond paste.

A constant load cell and a load ring sensor were used for studying the influence of tensile load on the electrode potential. The scanned area with SKP was the thinner central part of the specimen, to which deformation was concentrated see Fig. 1C. The specimen was deformed using a constant load cell applying loads in the range of 350-650 MPa. Finite element modeling (FEM) was used for modeling stresses and displacements in the matrix when a deformation of $10 \%$ (corresponding to a stress of $650 \mathrm{MPa}$ ) was applied, see Fig. 2.

For compression testing, flat specimens of dimensions $40 \times 40 \mathrm{~mm}$ were used, see Fig. 1B. Plastic deformation was locally done by indenting a metal cylinder $(\varphi=10 \mathrm{~mm})$ on the specimen surface for $10 \mathrm{~s}$, as shown in Fig. 1.

Surface characterization by GDOES. - The thickness and composition of the oxide film on the steel surface was characterized

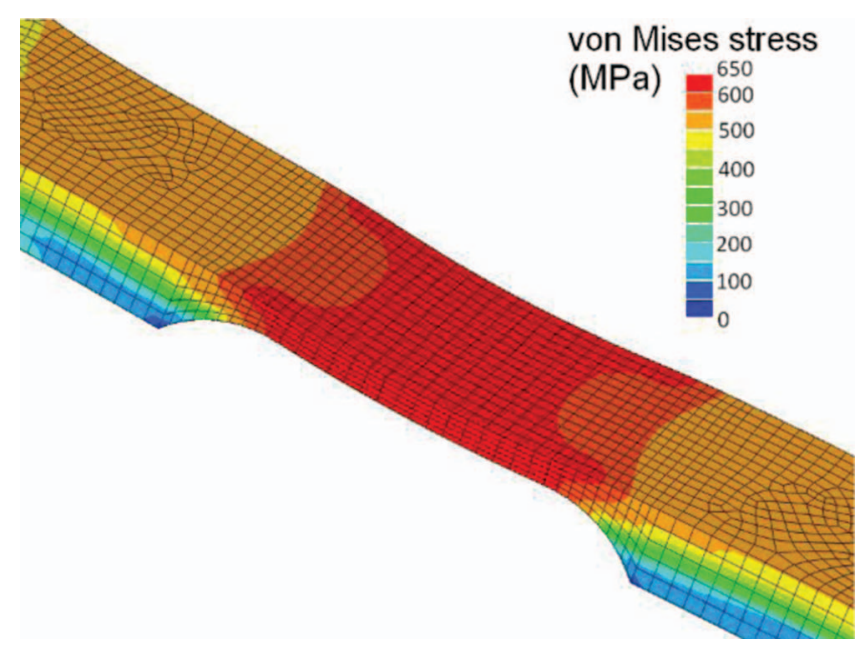

Figure 2. Von Mises stress calculated by FEM at $10 \%$ of strain (650MPa applied stress) showing a plastic deformation in the centre part of the specimen. 
by radio-frequency glow discharge optical emission spectroscopy (GDOES). GDOES depth profiles were recorded using LECO GDS 850A equipment. In this technique, a low pressure Ar-plasma is used to sputter atoms from the sample which lead to optical emission following excitation. The concentration of up to 30 elements can be obtained simultaneously by quantifying the amount of emitted light at specific wavelengths, which are distinctive for each element. For the GDOES measurements, the diameter of the area analyzed was $4 \mathrm{~mm}$ with a depth resolution of $10 \mathrm{~nm}$. Specimens had dimensions $40 \times 40 \mathrm{~mm}$ and were analyzed after various elapsed times following polishing with diamond paste $1 \mu \mathrm{m}$ or wet grinding on $\mathrm{SiC}$ \#80 paper.

Atomic force microscopy.- Atomic Force Microscopy (AFM) was used for studying the influence of plastic deformation on surface topography and roughness. The equipment used was an AFM BRUKER (nanoscope multimode 8) with tapping mode and a cantilever frequency of $354.83 \mathrm{KHz}$. The distance between points was varied between 5 and $10 \mathrm{~nm}$. The test was performed on $50 \times 50 \mu \mathrm{m}$ area polished with diamond paste $1 \mu \mathrm{m}$.

X-Ray diffraction.- X-Ray Diffraction (XRD) was performed on a D8 equipment model (Bruker AXS) to study the phases present in the material after application of plastic deformation. The XRD used has a parallel beam arrangement by Goebbel mirror, $1.2 \mathrm{~mm}$ divergence slit, and long Soller slits with a SolX (Bruker) energy dispersive detector used for identifying the phases.

The primary focus was the formation of deformation martensite, as $301 \mathrm{LN}$ is a metastable austenitic stainless steel.

\section{Results}

Influence of the surface preparation and elapsed time on the electrode potential and passive film thickness.

In order to study the influence of the time after surface preparation on the electrode potential, the surface of the specimens was scanned with SKP. The left hand side of Fig. 3 shows that the potential was fairly uniform at $\sim+300 \mathrm{mV}$ when measured $96 \mathrm{~h}$ after wet grinding to $\mathrm{SiC} \# 600$ paper. Abrading the right side of the specimen to $\mathrm{SiC}$ \#4000 paper only $1 \mathrm{~h}$ before the measurement resulted in a potential which was approximately $250 \mathrm{mV}$ lower. However, after an elapsed time of $48 \mathrm{~h}$ this potential returned to the original level of about $+300 \mathrm{mV}$.

The same trend of increasing potential with time following abrasion is also seen in the compiled data in Fig. 4, where the potential vs. time is shown both after grinding with $\mathrm{SiC} \mathrm{\# 80} \mathrm{paper} \mathrm{and} \mathrm{polish-}$

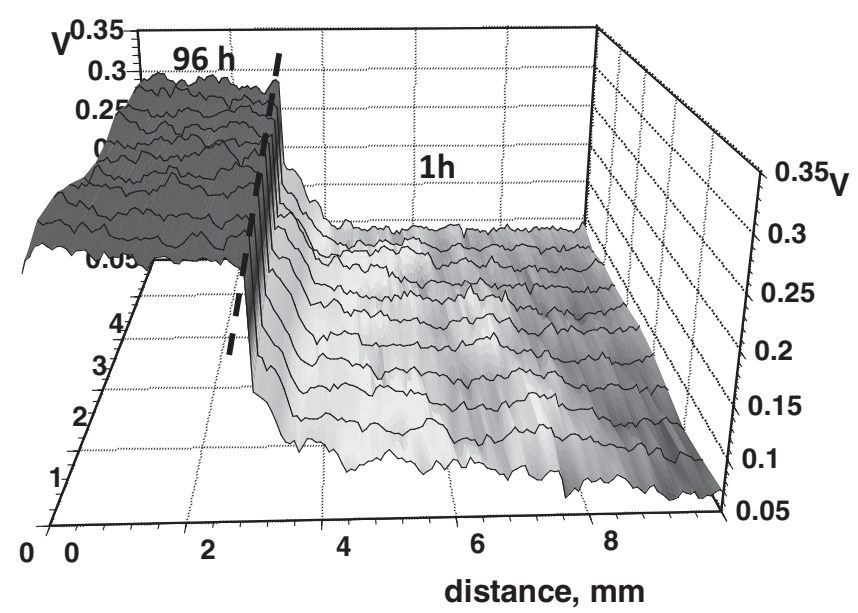

Figure 3. Potential profiles for steel $301 \mathrm{LN}$ where the left hand side was ground to SiC \#6096 h before testing, while the right hand side was carefully re-polished on SiC \#4000 $1 \mathrm{~h}$ before the SKP measurements

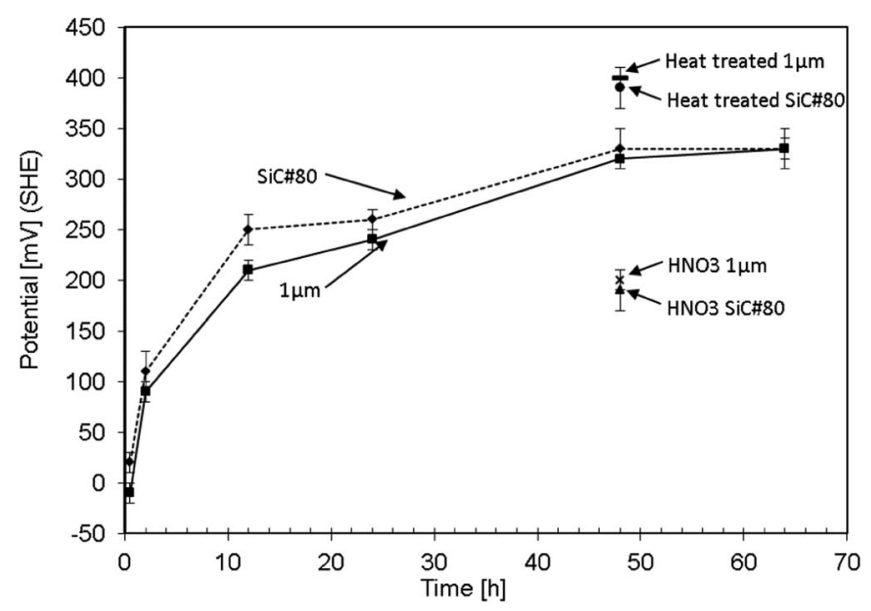

Figure 4. Changes of the stainless steel surface potential determined with SKP during exposure in air after polishing with $\mathrm{SiC} \# 80$ paper or $1 \mu \mathrm{m}$ diamond paste. The potential increases with time and stabilizes after $\sim 48 \mathrm{~h}$ independently of the roughness. Heat treatment led to higher potentials whereas an acid treatment decreased the surface potential. Mean values of X specimens based on duplicate tests.

ing with $1 \mu \mathrm{m}$ diamond paste. The rougher surface causes a slightly more pronounced increase in potential. However, after $48 \mathrm{~h}$ of exposure in air the potential of all the specimens stabilized in the range $310-330 \mathrm{mV}$ with no significant influence of the surface roughness. The potential for specimens $48 \mathrm{~h}$ after being treated in aqueous solution of $30 \mathrm{vol} \% \mathrm{HNO}_{3}$ was lower than for the corresponding specimens without the acid treatment. In contrast, specimens which were heat treated at $100^{\circ} \mathrm{C}$ for $15 \mathrm{~h}$ exhibited a higher potential of $380-400 \mathrm{mV}$.

A parallel study was performed using GDOES to examine the evolution of the composition and thickness of the passive film, see Fig. 5. This technique provides information about the elemental composition of the passive film, although it does not reveal details such as the hydroxide content. The surfaces were ground with $\mathrm{SiC} \# 80$ paper then analyzed after elapsed times of $0.5,4$, and $48 \mathrm{~h}$. The oxide thickness was defined as the thickness at which the oxygen level was half of the difference between maximum and minimum values, see Fig. 5. The same experiment was done for specimens diamond polished to $1 \mu \mathrm{m}$. The results showed that the native passive film had a total thickness in the range of $2-4 \mathrm{~nm}$, which increased with the elapsed time after preparation. In Fig. 6, the thickness of the passive film versus time for all the specimens is given. Larger thicknesses are measured for longer exposure times and no clear effect of roughness is observed. Heat treatment at $100^{\circ} \mathrm{C}$ for $15 \mathrm{~h}$ increased the thickness of oxide layer to about 5-6 nm.

The composition of the passive films was studied by studying the relative metal levels from GDOES profiles, see Fig. 7. The composition of the oxide is characterized by an outer layer of $\mathrm{Fe}$ and $\mathrm{Ni}$ oxide and an inner chromium-enriched oxide, independent of surface roughness or elapsed time. No depletion of chromium under the passive film was observed for any of the specimens. These results are generally in good agreement with passive film analyses in the literature, ${ }^{4,31-33}$ e.g. Hakiki showed that passive films have an inner region of $\mathrm{Cr}$ at the film-substrate interface $\left(\mathrm{Cr}_{2} \mathrm{O}_{3}\right)$ and an outer region of mixed iron and nickel oxides. ${ }^{34}$

Influence of plastic and elastic tensile stress on the electrode potential. - To investigate the influence of mechanical load on the electrode potential, a load of $350 \mathrm{MPa}$ for elastic deformation or $650 \mathrm{MPa}$ for plastic deformation was applied. The specimens were tested $48 \mathrm{~h}$ after polishing with $1 \mu \mathrm{m}$ diamond paste. The zone where the stresses are concentrated is located between the positions 6 to $16 \mathrm{~mm}$ in the SKP figures. The initial potential for a non-deformed 

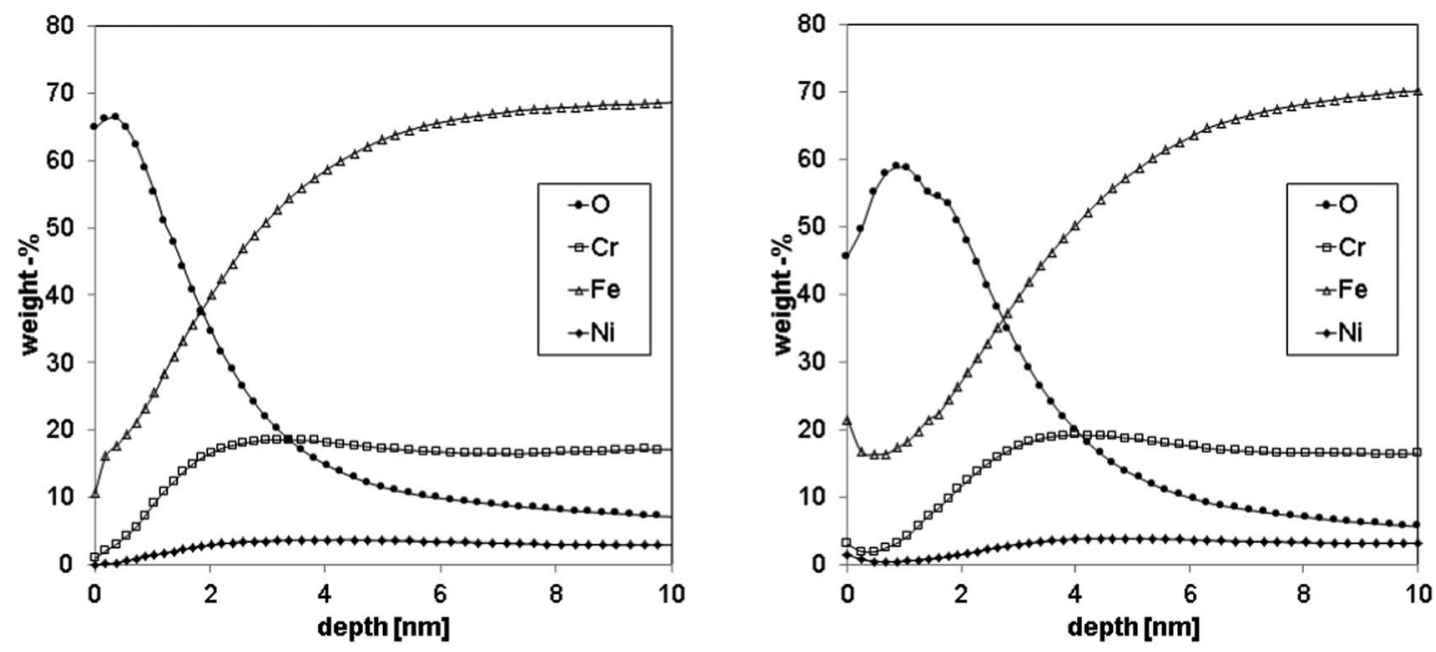

Figure 5. GDOES compositional depth profiles through passive films $5 \mathrm{~min}$ (left) and $48 \mathrm{~h}$ (right) after polishing with $\mathrm{SiC} \# 80$ showing Cr, Fe rich oxide. Oxide thickness is indicated by the vertical line.

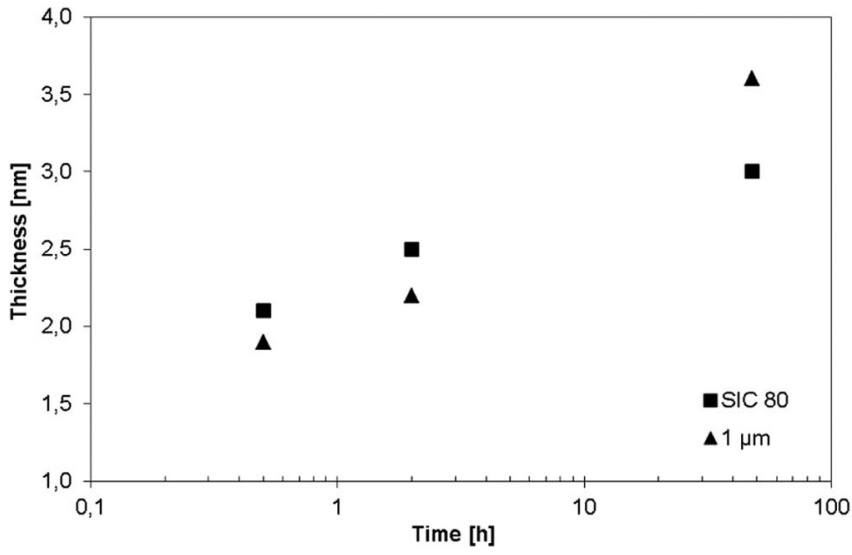

Figure 6. Passive film thickness at various elapsed times in air after grinding with $\mathrm{SiC} \# 80$ paper or polishing to $1 \mu \mathrm{m}$ diamond paste. Thickness increased with time for both surface conditions.

surface was in the range $300-350 \mathrm{mV}$. When an elastic load was applied, the potential in the deformed region increased by $30-70 \mathrm{mV}$, see Fig. 8. This effect was reversible when the load was removed. When the higher load level to give plastic deformation was applied, the potential in the central part of the specimen decreased by $\sim 150 \mathrm{mV}$ to a level of 150-200 mV, see Fig. 9. In contrast to the elastic loading, this change of potential was irreversible.

The same procedure was done for a specimen which had been heat treated at $150^{\circ} \mathrm{C}$ for $18 \mathrm{~h}$ prior to loading. The heat-treatment increased the oxide thickness to $5-6 \mathrm{~nm}$. The initial potential of this specimen was $400 \mathrm{mV}$ which is significantly higher than the non-heat-treated specimens. In this case, the potential decreased by $\sim 250 \mathrm{mV}$ in the plastically deformed area compared to the nondeformed area, resulting in a similar potential level as for plastically deformed specimens which had not been heat treated.

The effect of acid treatment under plastic deformation is shown in Fig. 10. A load of $650 \mathrm{MPa}$ decreased the potential by $\sim 150 \mathrm{mV}$ (Fig. 10, left). Without unloading, the sample was immersed in an aqueous solution of $30 \% \mathrm{HNO}_{3}$ for $30 \mathrm{~min}$., rinsed in de-ionized water and dried in a flow of compressed air. The SKP profile $1 \mathrm{~h}$ after the acid treatment (Fig. 10, right) shows that the potential on the loaded section dropped by a further $\sim 50 \mathrm{mV}$ while that for the unstressed edges dropped by $\sim 200 \mathrm{mV}$. Only a small difference in the potential thus remained between the stressed and unstressed areas of the specimen.

SKP was used to measure the electrode potential of a specimen plastically deformed by indentation. The specimens were tested $48 \mathrm{~h}$
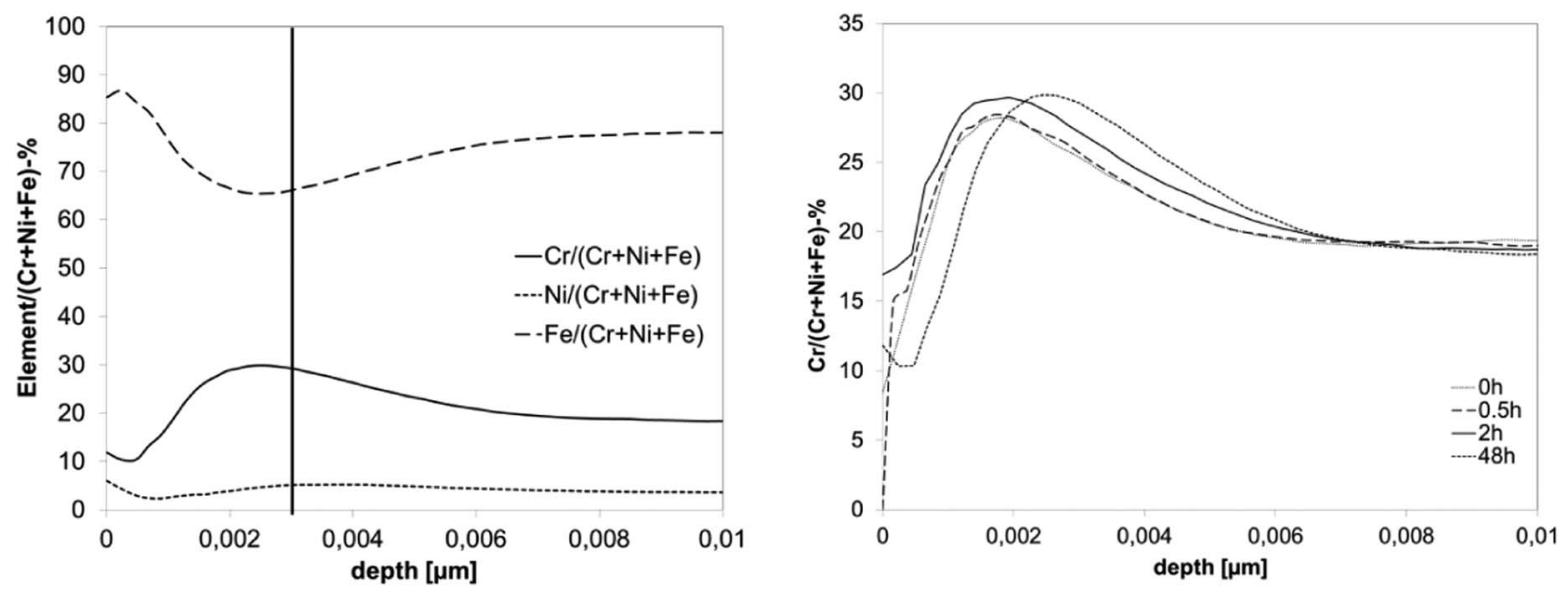

Figure 7. Relative levels of chromium, nickel and iron in the passive film $48 \mathrm{~h}$ after grinding with $\mathrm{SiC} \# 80$ and chromium fraction depth profile after $0-48 \mathrm{~h}$. Composition of the passive film is independent of the roughness and no chromium depletion was observed in any of the specimens. 

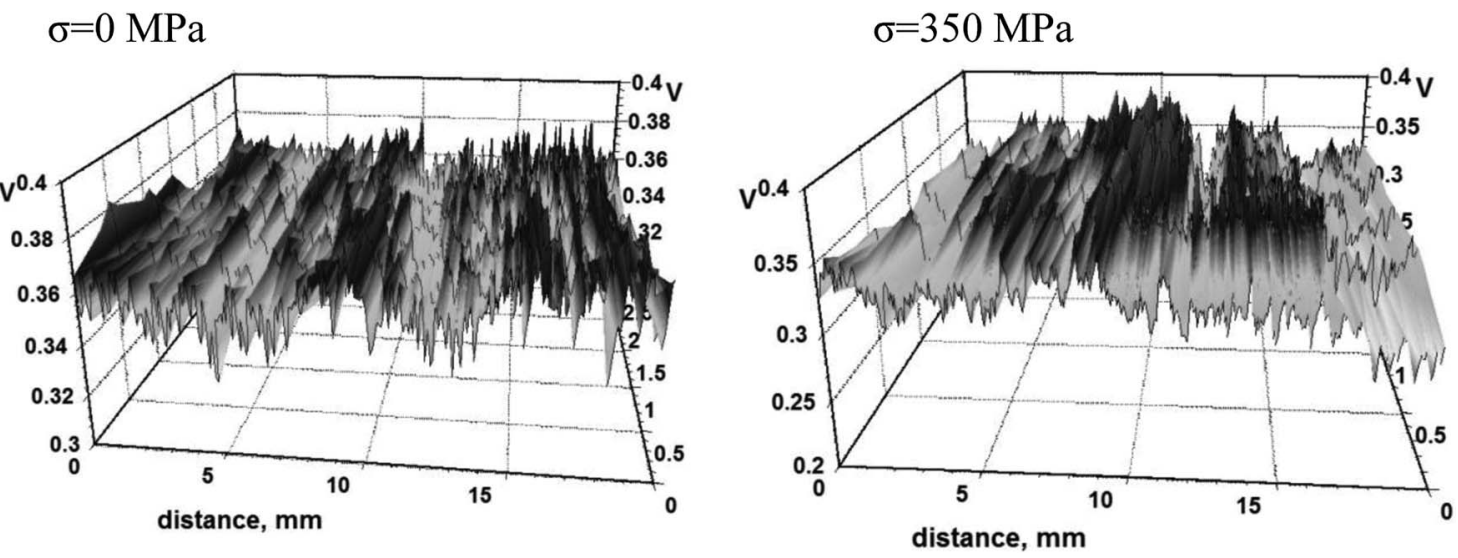

Figure 8. Electrode potential profiles of a specimen before loading (left) and under elastic load of $350 \mathrm{MPa}$ (right). The specimens were tested $48 \mathrm{~h}$ after grinding with $\mathrm{SiC} \# 600$. The elastic deformation increased the potential by $30-70 \mathrm{mV}$.
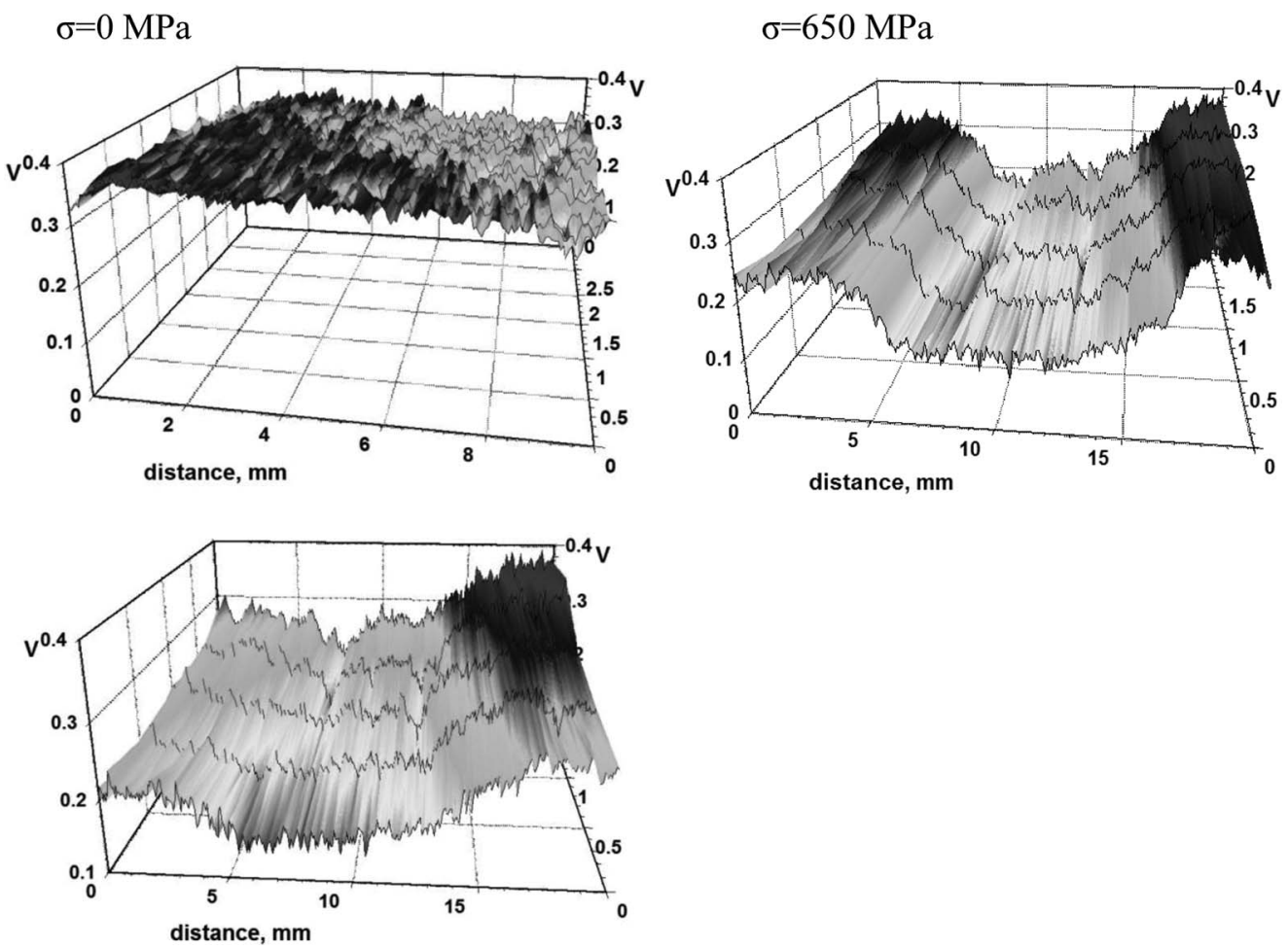

Figure 9. Electrode potential profiles of a specimen before loading (top, left), under a plastic load of $650 \mathrm{MPa}$ (top, right) and $24 \mathrm{~h}$ after removing the load (bottom, left). The potential decreased irreversibly by $\sim 150 \mathrm{mV}$ when plastic deformation was applied.
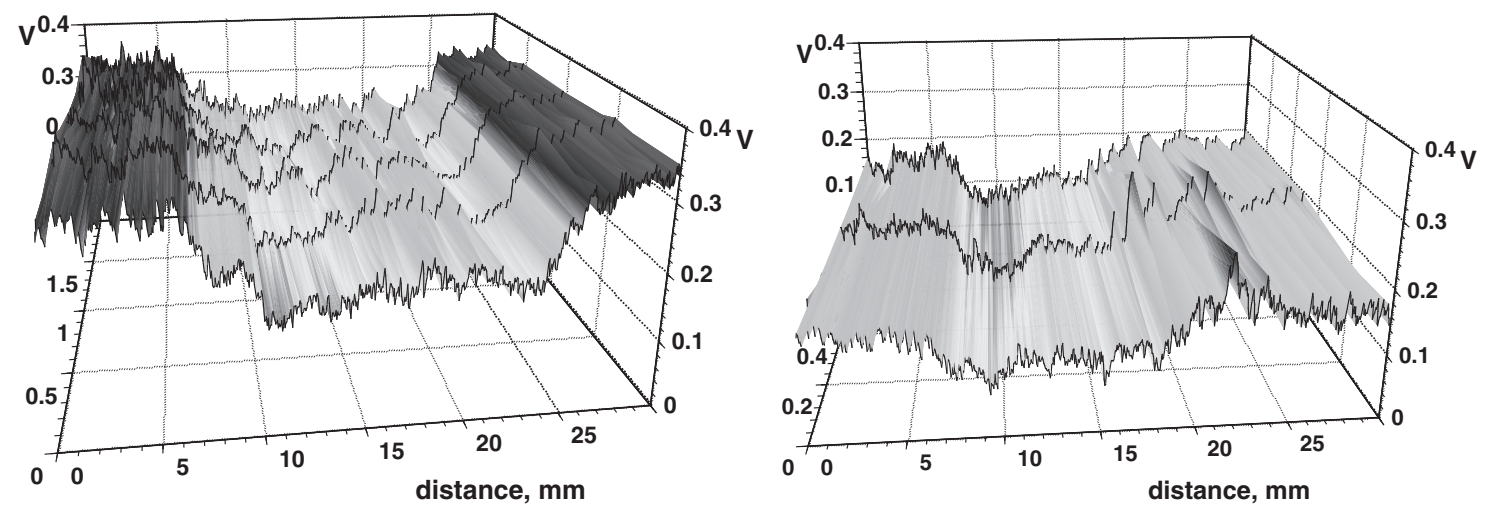

Figure 10. Electrode potential profiles under 650MPa before (left) and after (right) 30 vol. $\% \mathrm{HNO}_{3}$ surface treatment showing a decrease of potential by $100 \mathrm{mV}$ after the acid treatment. 
A. Electrode potential before indentation

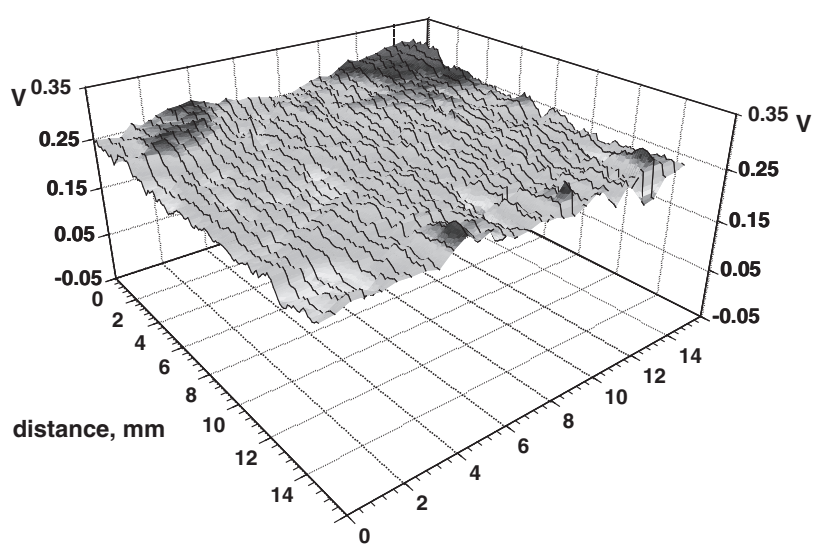

C. Electrode potential map after indentation

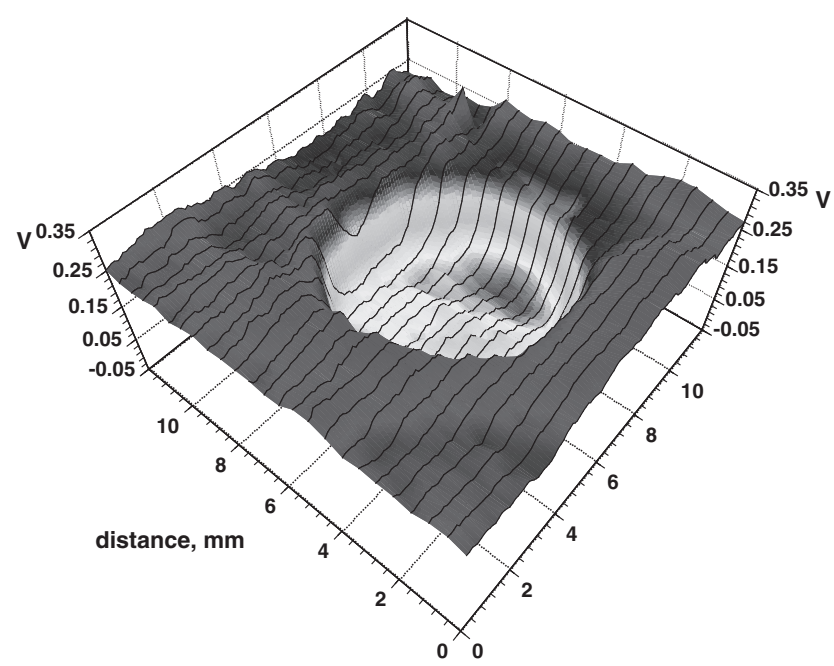

B. Topography

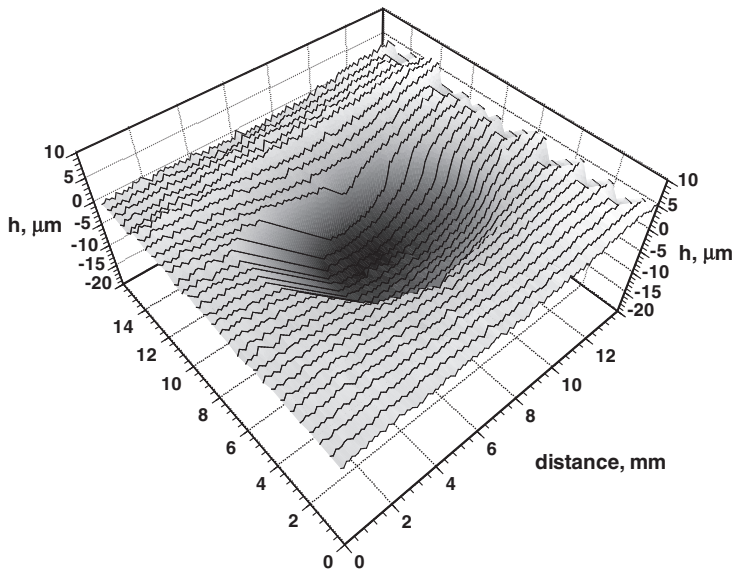

D. Electrode potential map after passivation

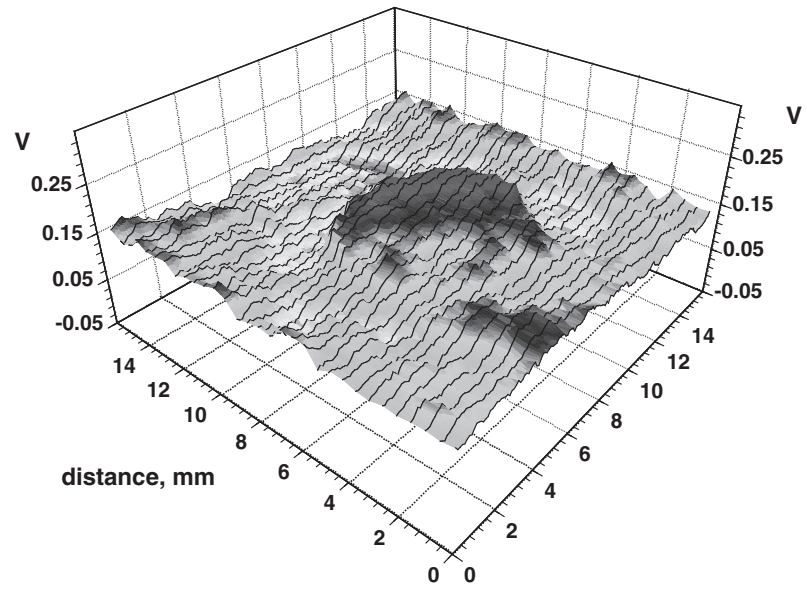

Figure 11. Potential profiles (A, C, D) and topography (B). Before (A) and after indentation (B, C, D). Potential profile after treatment in the 30 vol.\% nitric acid (D).

after polishing with $1 \mu \mathrm{m}$ diamond paste. The initial potential shown in Fig. $11 \mathrm{~A}$ is in the range of $250-300 \mathrm{mV}$. The topography of the specimen after indentation, Fig. 11B, was measured and used for compensating the difference of height when measuring the potential profile.

It was seen that the potential decreased by approximately $250 \mathrm{mV}$ in the deformed region, reaching a value of $0 \mathrm{mV}$. The process was largely irreversible, although the potential in the deformed region increased to $10-20 \mathrm{mV}$ after $24 \mathrm{~h}$ of exposure in air. The same specimen was thereafter treated in $30 \mathrm{vol} \% \mathrm{HNO}_{3}$, rinsed in de-ionized water and dried, see Fig. 11D. As was seen for the tensile specimen, the nitric acid treatment decreased the potential of the unstressed edges of the specimen. However, different behavior was seen for the centre of the compressed area, which increased in potential after the nitric acid treatment to a similar level as before loading.

The effect of plastic deformation on surface topography and roughness for specimen with an applied tensile load of $650 \mathrm{MPa}$ was studied using AFM, Fig. 12. The specimen was polished with $1 \mu \mathrm{m}$ diamond paste prior to deformation. The results showed that plastic deformation increased the roughness from $50 \mathrm{~nm}$ to $1 \mathrm{~mm}$ and produced characteristic slip steps on the surface.

Plastic deformation can also lead to phase transformation in the steel. XRD analysis of deformed and non-deformed regions of a tensile

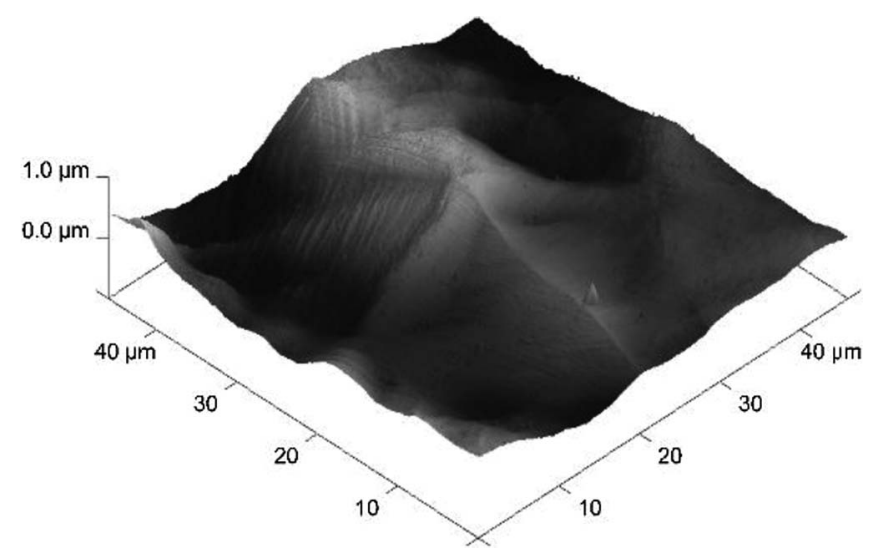

Figure 12. 3D topography using AFM of the plastic deformed zone of a specimen after tensile testing showing slip planes on the deformed surface. 


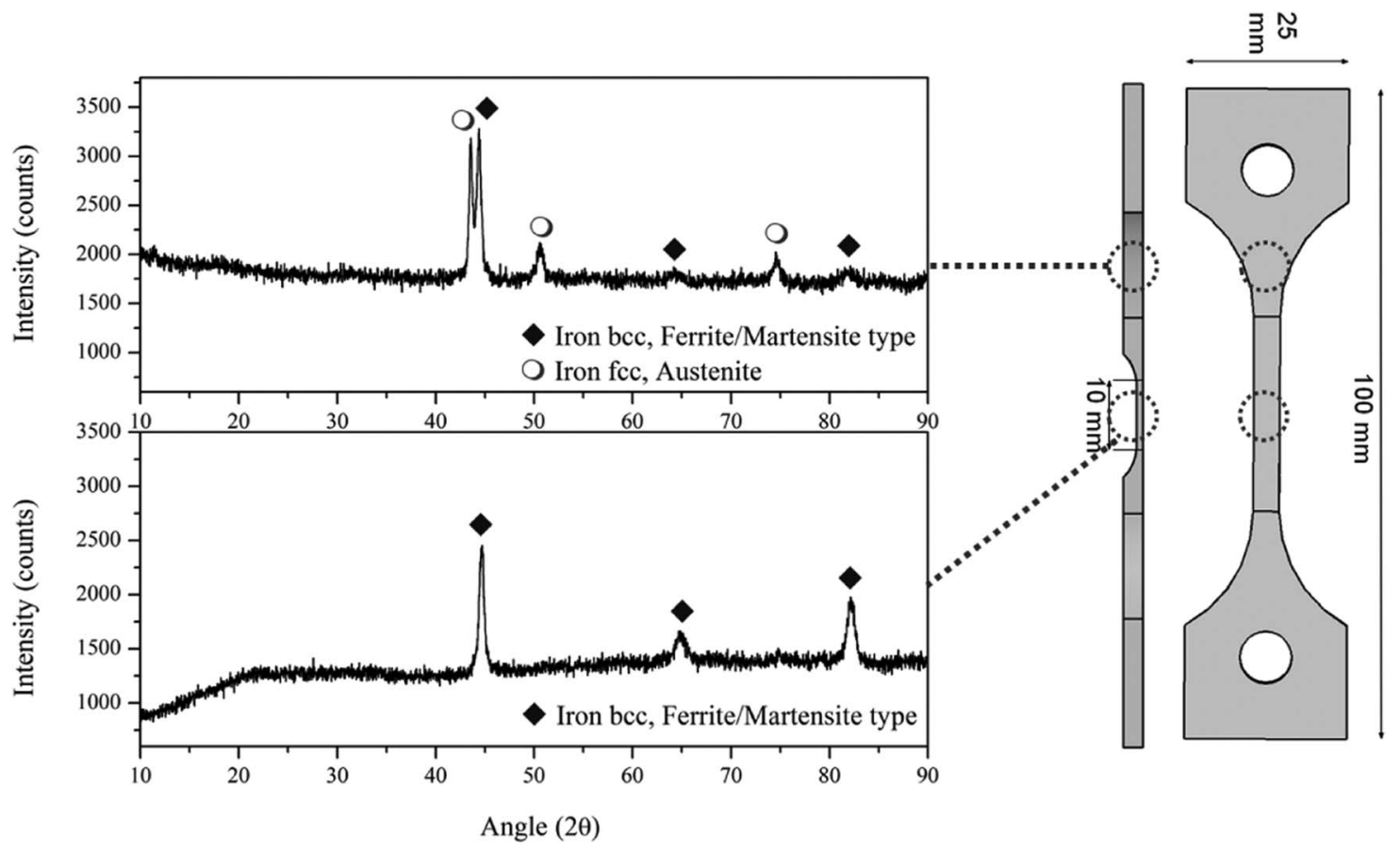

Figure 13. X-Ray diffraction of deformed and non-deformed regions in a plastically deformed specimen after tensile testing.

specimen indicated that plastic deformation induced a transformation of the austenite into martensite, from about $48 \%$ in the unloaded condition to $100 \%$, see Fig. 13.

\section{Discussion}

In this work the effect of passive film thickness, roughness and applied stress on the electrode potential was measured for an austenitic stainless steel grade $301 \mathrm{LN}$ using a scanning Kelvin probe.

The experimental results are in agreement with previous work showing that the electrode potential is strongly dependent on the strain level and the thickness of the oxide film. ${ }^{26,23}$ Tensile testing in the elastic stress domain increased the potential (Fig. 8) whereas a plastic load, either compressive or tensile, decreased the potential (Fig. 9 and Fig. 11). The effect of deformation on the potential was more pronounced for plastic than elastic deformation; a load of $650 \mathrm{MPa}$ decreased the potential by $150 \mathrm{mV}$ and an elastic load of $350 \mathrm{MPa}$ increased it by $30-70 \mathrm{mV}$. These results are in agreement with EWF measurements for elastically strained copper, aluminum and duplex steel that were presented in the Introduction section. ${ }^{18,22,23,30}$

Interpretation of the measurements is complicated by the simultaneous occurrence of numerous effects, such as oxide thickness, composition, dislocations formation, donors/acceptors density, roughness and martensite formation.

Published work has attributed the increase of potential during elastic deformation to the increase of nano-roughness on the surface of the metal. ${ }^{23}$ It was shown that electrode potential reached its maximum point before plastic deformation started. The theoretical explanation proposed by Wang et al. ${ }^{23}$ is that elastic tension decreases the density of the atomic packing and decreases the concentration of the electrons in the metal layer close to the interface, this makes the Fermi level electrons bind more strongly at the surface so it is more difficult for them to escape, consequently increasing the potential. On the other hand, it has been pointed out by Feng et al. that a potential drop across the adsorbed layer also contributes to SKP measurement. Oxygen molecules accept electrons from the oxide, creating a dipole with negative charge on the oxygen and positive (hole) in the oxide film. ${ }^{10}$ This orientation takes place on oxidized metals and increases the electrode potential. Thus the ennoblement of potential can be related to strain induced oxygen adsorption. Both of these explanations appear relevant to the current observations.

When plastic load is applied, slip bands emerge to the surface, see Fig. 12, and can rupture the surface oxide so that the electrons on the Fermi level can be more easily released. The "slip dissolution" model for stress corrosion cracking is based on the same type of concept: that dislocation motion along slip bands causes breaks in the passive film, creating locally active areas on slip bands. It therefore seems reasonable to conclude that the rupture of the passive film is the main effect causing the decrease in the electrode potential during yielding. ${ }^{26}$ Plastic deformation of the metastable austenitic stainless steel 301LN also leads to a change of the microstructure of the steel, increasing the amount of martensite from $\sim 50 \%$ to $100 \%$ (Fig. 13). ${ }^{13}$ The formation of martensite can also cause rupture of the passive film and decrease its protectiveness, and consequently the EWF. ${ }^{13}$

The contribution of passive film thickness to the EWF is an important parameter to study because it affects the baseline potential against which changes induced by stress are compared, and because during tensile testing a reduction of the passive film thickness occurs. ${ }^{4}$ The present work showed that the electrode potential appears to be proportional to the oxide thickness, with both parameters increasing immediately after polishing and reaching a steady-state after $48 \mathrm{~h}$ (Fig. 4 and Fig. 6). The oxide film thickness increases with time due to the continuous reaction of oxygen with elements of the bulk metal and reaches a steady-state after some time as it is limited by the diffusion process of anion/cations through the passive film. ${ }^{34}$ The connection between high EWF and thicker oxides was also indicated; higher potentials were measured on thicker oxides obtained after heat-treatment at $150^{\circ} \mathrm{C}$ and, on the contrary, lower potentials were measured for thinner oxides obtained after immersion in $30 \mathrm{vol} . \% \mathrm{HNO}_{3}$, Fig. 4. Similar results were also reported in previous work which showed a lower capacitance for thinner passive films formed in acidic environments. ${ }^{5}$ However, these results are in disagreement with the fact that nitric acid is widely used in the industry for enhancing the corrosion resistance of stainless steels. Previous work also stated that nitric acid passivation increases the thickness of the passive film ${ }^{35}$ and the $\mathrm{Cr} / \mathrm{Fe}$ ratio. ${ }^{36} \mathrm{~A}$ complicating factor in this respect is that heat-treatment or acid treatment may also affect the defect structure or hydroxyl fraction of the passive film. The latter has been shown by Özkanat et al. ${ }^{38}$ to 
have a significant effect on the potential. It therefore seems that there is scope for more work to identify conditions in which different types of treatment have beneficial or detrimental effects on the passive film.

The dominating effect of film rupture, regardless of oxide thickness, on the electrode potential was demonstrated when measurements were made under the same load on specimens with different oxide thickness. A larger EWF drop was measured for the specimens which had first been heat treated to give a thicker oxide than for specimens with thinner oxides. However, the final potential level was similar in both cases.

As discussed above, plastic load gives rise to rupture and thinning of the passive film and an increase in the surface roughness. In order to separate these effects, measurements of the potential were made for specimens with different surface preparation, which give rise to different surface roughness (Fig. 4). It was found that the potential was lower for rough surfaces than smooth surfaces, but that the effect was only small and gradually disappeared with time. A possible explanation is that rougher grinding introduces compressive residual stresses in the metal surface that influence on the semi-conductivity properties of the oxide. ${ }^{32,37}$ Residual stresses contribute also to the formation of dislocations and increase the presence of donors-acceptors in the oxide that reduce the potential. ${ }^{5,37}$ Measurements of the potential for passive films of different thickness after different elapsed times following grinding likewise indicate that the roughness effect is minor within the range induced by plastic deformation, e.g. the highest electrode potential difference due to roughness effect was $20 \mathrm{mV}$ after $48 \mathrm{~h}$ whereas plastic deformation induced a change of $150 \mathrm{mV}$. The dominant effect giving rise to the potential drop following plastic deformation is therefore concluded to be passive film rupture.

Surface roughness and damage are also feasible explanations for the potential drop measured on specimens after indentation testing. The potential drop was larger than that measured after plastic deformation in tensile testing. The larger effect of indentation testing could be attributed to damage on the surface due to the contact of the indentation cylinder, which may create scratches and more breaks in the oxide.

A significant difference between elastic and plastic deformation effects on electrode potential was that the small increase in the potential due to elastic deformation was immediately reversed when the load was removed. In contrast, the decrease in potential after plastic deformation was still apparent $24 \mathrm{~h}$ after removal of the load. The implications of this observation are that the strain history of a material will have consequences for the electrochemical response and the susceptibility to corrosion.

\section{Conclusions}

1. This work demonstrates that SKP is a valuable electrochemical technique to study the effect of strain on $301 \mathrm{LN}$ without application of an electrolyte.

2. There is a clear correlation between the electrode potential and the passive film properties. A thicker oxide film gives a nobler potential, while a rougher surface exhibits a slightly lower potential.

3. Application of an elastic tensile load increased the electrode potential slightly, but this effect was immediately reversed when the stress was removed. In contrast plastic strain by tensile and com- pressive testing strongly decreased the potential and this effect remained even after removal of the stress. The effect of plastic deformation was attributed to rupture of the passive film by dislocation motion along slip bands and martensite formation. Additional effects such as density of donors/acceptors may also contribute.

\section{Acknowledgments}

The authors would like to thank Mats Randelius and Aldin Delic, Swerea KIMAB AB, Sweden for GDOES measurements and Philippe ELIES, Brest University, France for AFM measurements.

\section{References}

1. B. D. Craig, Fundamental Aspects of Corrosion Films in Corrosion Science, Springer US, Boston, MA (1991).

2. R. W. Staehle, in NACE-5, R. W. Staehle, J. Hochmann, and R. D. McCright, Editors, p. 180, NACE, Houston, TX (1977).

3. E. M. Gutman, Corros. Sci., 49, 2289 (2007).

4. F. Navaï and O. Debbouz, J. Mater. Sci., 34, 1073 (1999).

5. V. Vignal, C. Valot, R. Oltra, M. Verneau, and L. Coudreuse, Corros. Sci., 44, 1477 (2002).

6. J. Kovač, T. Kosec, and A. Legat, Corros. Eng. Sci. Technol., 47, 478 (2012).

7. J. Orlikowski, K. Darowicki, A. Arutunow, and W. Jurczak, J. Electroanal. Chem., 576, 277 (2005)

8. C. M. Rangel, T. M. Silva, and M. da C. Belo, Electrochim. Acta, 50, 5076 (2005).

9. L. Jinlong and L. Hongyun, Appl. Surf. Sci., 263, 29 (2012).

10. X. Feng, X. Lu, Y. Zuo, and D. Chen, Corros. Sci., 82, 347 (2014).

11. J. G. Hines and T. P. Hoar, "The Stress Corrosion Cracking of Austenitic Stainless Steels: Part II, Fully Softened, Strain-Hardened, and Refrigerated Material." J. Iron Steel Inst., London, 184, 166 (1956).

12. Y. Fu et al., Electrochim. Acta, 54, 1618 (2009).

13. P. M. de O. Silva, H. F. G. de Abreu, V. H. C. de Albuquerque, P. de L. Neto, and J. M. R. S. Tavares, Mater. Des., 32, 605 (2011).

14. T. Yamamoto, K. Fushimi, S. Miura, and H. Konno, ECS Trans., 25, 3 (2010).

15. R. Hausbrand, M. Stratmann, and M. Rohwerder, J. Electrochem. Soc., 155, C369 (2008).

16. S. Trasatti and R. Parsons, J. Electroanal. Chem. Interfacial Electrochem., 205, 359 (1986).

17. R. Smoluchowski, Phys. Rev., 60, 661 (1941)

18. X. F. Wang, W. Li, J. G. Lin, and Y. Xiao, EPL, 89, 66004 (2010).

19. W. H. S. S.-M. Huang, S. Yee, R. T. Atanasoski, C. S. McMillan, and R. A. Oriani, J. Electrochem. Soc., 138, L63 (1991).

20. W. Li and D. Y. Li, Appl. Surf. Sci., 240, 388 (2005).

21. W. Li, M. Cai, Y. Wang, and S. Yu, Scr. Mater, 54, 921 (2006).

22. W. Li, Y. Wang, and D. Y. Li, Phys. status solidi, 201, 2005 (2004)

23. R. J. Wang, J. X. Li, Y. J. Su, L. J. Qiao, and A. A. Volinsky, Procedia Mater. Sci., 3, 1736 (2014)

24. S. V. Loskutov, Surf. Sci., 585, L166 (2005).

25. V. V. Levitin, O. L. Garin, V. K. Yatsenko, and S. V. Loskutov, Vacuum, 63, 367 (2001).

26. A. Nazarov and D. Thierry, Electrochim. Acta, 52, 7689 (2007).

27. W. G. Qin and D. Shaw, Phys. B Condens. Matter, 404, 2247 (2009).

28. M. Rohwerder and F. Turcu, Electrochim. Acta, 53, 290 (2007)

29. M. Stratmann and H. Streckel, Corros. Sci., 30, 681 (1990).

30. J. Hölzl and F. K. Schulte, Solid Surf. Physics, Springer, New York (1979).

31. M. F. Montemor, M. G. S. Ferreira, N. E. Hakiki, and M. Da Cunha Belo, Corros. Sci., 42, 1635 (2000).

32. V. Vignal, C. Valot, R. Oltra, M. Verneau, and L. Coudreuse, Corros. Sci., 44, 1477 (2002).

33. N. E. Hakiki, J. Appl. Electrochem., 38, 679 (2008).

34. N. E. Hakiki, Corros. Sci., 53, 2688 (2011)

35. Y. Zhao, C. Q. Cheng, Z. Y. Cao, and J. Zhao, Mater. Charact., 77, 1 (2013).

36. C. O'Laoire, B. Timmins, L. Kremer, J. D. Holmes, and M. A. Morris, Anal. Lett., 39, 2255 (2006)

37. G. Bäck, A. Nazarov, and D. Thierry, Corros. Sci., 61, 951 (2005).

38. Ö. Özkanat et al., J. Phys. Chem. C, 116, 1805 (2012). 